Bréart G. Relation between pain symptoms and the anatomic location of deep infiltrating endometriosis Fertil Steril 2002; 78: 719-726.

6 Porpora MG, Koninckx PR, Piazze J, Colagrande S, Cosmi EV. Correlation between endometriosis and pelvic pain. $J A m$ Assoc Gynecol Laparosc 1999; 6: 429-434.

7 Vercellini P. Endometriosis: what a pain it is. Semin Reprod Endocrinol 1997; 13: 251-261.

8 Momoeda M, Taketani Y, Terakawa N, Hoshiai H, Tanaka K, Tsutsumi $\mathrm{O}$, et al. Is endometriosis really associated with pain?
Gynecol Obstet Invest 2002; 54(Suppl. 1): 18-21.

9 Bryman A. Social Research Methods. Oxford, UK: Oxford University Press, 2001.

10 Graham H. Surveying through stories. In: Social Researching: Politics, Problems, Practice, Bell C, Roberts H (eds). London, UK: Routledge \& Kegan Paul, 1984; 104-204.

11 Bowling A. Research Methods in Health (2nd edn). Maidenhead, UK: Open University Press, 2002.

12 Denny E. Women's experience of endometriosis. J Adv Nurs 2004; 46: 641-648.

\title{
Sexual health networks: linking providers for improvement
}

\author{
Paula Baraitser, Gary Alessio, Michael Brady
}

\section{Why was change needed?}

The National Health Service (NHS) is changing. New management structures and financial pressures have put sexual health services at risk. Commissioners are as dismayed as service users by the numerous providers in the world of sexual health and find effective planning in this context difficult. Services that work together are stronger and speak louder to commissioners.

\section{How is the new service different?}

A network is a set of autonomous organisations that come together to reach goals that no one organisation can reach separately. They may collaborate within a formal structure with clear lines of accountability or an informal one based on close working relationships.

Many areas have already set up sexual health networks in response to specific local situations. Some focus on genitourinary medicine (GUM) and HIV while others focus on sexual and reproductive health services, health promotion or the teenage pregnancy strategy. The Lambeth and Southwark Sexual Health Network (LASSHNET) is one example of a sexual health network working to link service providers and help them speak to commissioners.

\section{How is the new service organised?}

LASSHNET emerged from the work of the Lambeth and Southwark Sexual Health Modernisation Programme. LASSHNET is a very broad organisation with clinicians and senior managers from sexual and reproductive health care, GUM, health promotion, public health, voluntary sector organisations, community pharmacy, general practice and commissioning. It has a full-time network development manager and 1 day per week each from two clinical leads.

The work of the Modernisation Programme that LASSHNET is now taking on includes demand and capacity mapping, waiting and transit times monitoring and a mystery shopper programme. The programme has generated new roles for community pharmacy and a new model of sexual health service provision. A key message

\section{J Fam Plann Reprod Health Care 2007; 33(3): 193}

Lambeth and Southwark Sexual Health Network, London, UK Paula Baraitser, MD, MFFP, Clinical Lead

Gary Alessio, BA, Network Development Manager

Michael Brady, MRCP, DipGUM, Clinical Lead

Correspondence to: Dr Paula Baraitser, Lambeth and Southwark Sexual Health Modernisation Programme, Masters House,

Dugard Way (off Renfrew Road), London SE11 4TH, UK.

E-mail: paula_baraitser@mac.com from this programme is that working across the whole system of sexual health service provision brings advantages.

\section{How does the new service work in practice?}

LASSHNET has functioned effectively as part of the Modernisation Programme which organised meetings, paid for cover to ensure attendance by senior clinicians/managers and provided a link between LASSHNET and senior management in all local Trusts.

\section{What benefits does the new service offer?}

Potential benefits of collaboration include:

- Consistent clinical protocols and agreed referral pathways

- Joint undergraduate and postgraduate training programmes

- Joint strategies for service monitoring and evaluation

- Coordinated recruitment and staff induction processes

- New ways of working that cut across traditional clinical boundaries

- An integrated approach to developing and funding the whole system of sexual health service provision.

For providers of community sexual and reproductive health services engagement with local networks should be a priority. A co-ordinated network of providers with clear messages will engage commissioners and lead to effective planning.

\section{The future}

LASSHNET has developed in ideal circumstances. However, the Modernisation Programme ceases in December 2007 and LASSHNET must now plan for sustainability and meet the challenges faced by sexual health networks across the country. The most important of these is finding an organisational home and funding for managerial and clinical support.

The learning from cancer networks is that LASSHNET must accept complexity to survive. Networks may be accountable to different organisations for specific aspects of their work, their staff may be employed by different Trusts and they may get funding from a wide variety of sources. But, paradoxically, as the organisations around them reconfigure, the collaborations that make up the network may provide some much needed continuity.

\section{Author's note}

The Lambeth and Southwark Sexual Health Modernisation Programme is a 3-year service improvement programme that aims to redesign sexual health services starting from the perspective of the service users. It is funded by the Guys and St Thomas' Charity. 